\title{
Seasonal variation in the Carbohydrate content from different tissues of Sepia aculeata in Pazhayar coastal waters, Nagapattinam District, Tamilnadu
}

\author{
S. Sumathi ${ }^{1}$, A. Christy Ponni ${ }^{2}$ * \\ ${ }^{1}$ Dept. of Zoology, TBML College, Porayar-609 305, Tamilnadu, India \\ ${ }^{2}$ Dept. of Zoology, TBML College, Porayar-609 305, Tamilnadu, India
}

Available online at: www.isroset.org

Received: 30/Aug/2018, Accepted: 25/Sept/2018, Online: 31/Oct/2018

Abstract: The aim of this work was to investigate the seasonal variability in the Carbohydrate content in Sepia aculeata during January 2017 to December 2017. The total carbohydrate was estimated in muscle, gill, liver and gonad.

Key words: Sepia aculeata, Muscle, Gill, Liver and Gonad.

\section{Introduction}

Class cephalopoda which include the Nautilus, Cuttle fish, Squid and Octopus is the most advanced class of phylum: Mollusca, adapted to a swimming existence. There are about 80 species of cephalopods of commercial and scientific interest distributed in the indian seas [1]. Biochemical composition of the whole body indicates the quality of cephalopods [2]. But the proximate the measurement of some proximate profiles such as Protein, Carbohydrate and Lipids is often necessary to ensure that they meet the requirements of food regulations \& commercial specifications [3]. However most of the previous studies concentrate on the proximate composition and nutritional evaluation of many commercially important fishes and few species of cephalopods. But at the same time limited work has been carried out in the different body parts of cephalopods Sepia aculeata. Therefore the present study was undertaken to evaluate the carbohydrate content of cuttlefish Sepia aculeata.

\section{Materials and Methods}

The specimen of S. aculeata collected from Pazhayar coastal water, south east coast of India. After collection, the animals were thoroughly washed with fresh water and put into ice box were brought to the laboratory. The different body parts such as muscle, gill, liver and gonad were dissected out. The respective tissues were used for carbohydrate estimation.

\section{Result and Discussion}

The carbohydrate content has been shown in the Table 1 and Figure 1 to 4 (Seasonal variations). In Sepia aculeata the carbohydrate content is high in female than the male [4]. Similar studies were carried out [5].

Muscle: The percentage of carbohydrate values in males fluctuated from $25.68 \%$ to $34.28 \%$ and in females from $30.60 \%$ to $32.26 \%$.

Gill: In males carbohydrate values varied from $25.06 \%$ to $31.86 \%$ and in females from $27.31 \%$ to $35.12 \%$.

Liver: In the Liver of male Sepia aculeata the carbohydrate values fluctuated from $25.08 \%$ to $30.75 \%$ and in females from $26.20 \%$ to $30.26 \%$.

Gonad: The percentage of carbohydrate values in males fluctuated from $29.02 \%$ to $36.20 \%$ and in females from $31.68 \%$ to $38.98 \%$.

In general carbohydrate values higher in females than the males in all the organs. Glycogen may be important for the maturation process and embryogenesis. Carbohydrates are precursors of metabolic intermediates in the production of energy and non essential amino acids and as a component in ovarian pigments [6]. In this present study total carbohydrate is decreased in summer to fall than increased slightly in monsoon [7] Similar observations have been recorded for $O$. vulgaris [8] and $L$. forbesi [9] Where the glycogens reserves are increased during maturation in the gonad and muscles. 
Table 1 Seasonal Variations in the carbohydrate content of Sepia aculeate (\%).

\begin{tabular}{|c|c|c|c|c|c|c|c|c|}
\hline \multirow{2}{*}{ Period } & \multicolumn{2}{|c|}{ Muscle } & \multicolumn{2}{c|}{ Gill } & \multicolumn{2}{c|}{ Liver } & \multicolumn{2}{c|}{ Gonad } \\
\cline { 2 - 10 } & Male & Female & Male & Female & Male & Female & Male & Female \\
\hline Post monsoon & 29.41 & 30.60 & 34.11 & 35.12 & 28.23 & 29.04 & 30.58 & 32.57 \\
\hline Summer & 25.68 & 27.52 & 32.10 & 33.26 & 27.58 & 28.53 & 29.02 & 31.68 \\
\hline Pre monsoon & 28.89 & 29.06 & 25.06 & 27.31 & 25.08 & 26.20 & 30.81 & 32.96 \\
\hline Monsoon & 34.28 & 32.26 & 31.86 & 32.28 & 30.75 & 30.26 & 36.20 & 38.98 \\
\hline
\end{tabular}

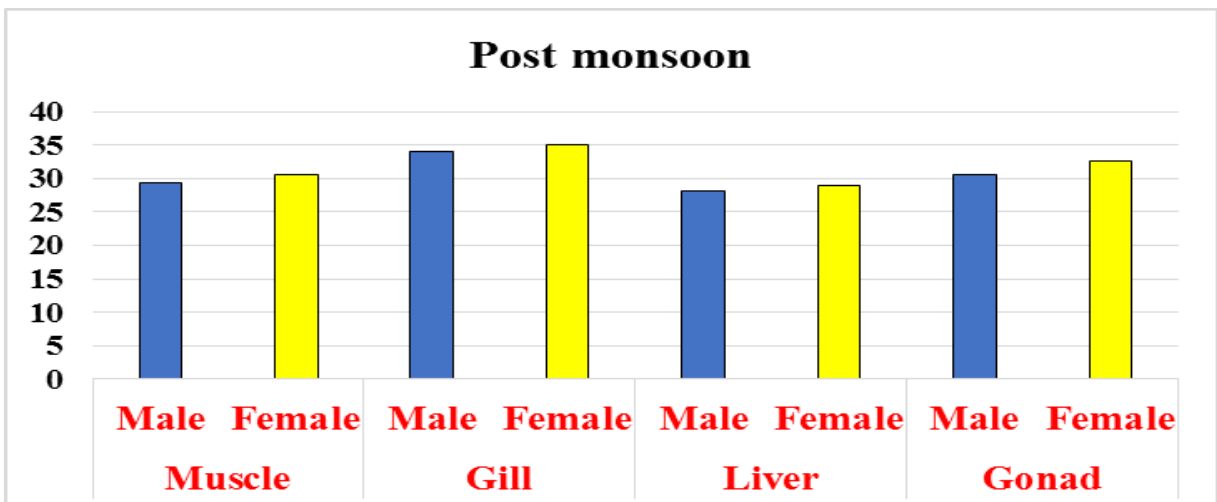

Figure 1 Seasonal variations in the Carbohydrate content (\%) of S. aculeata during post monsoon Season.

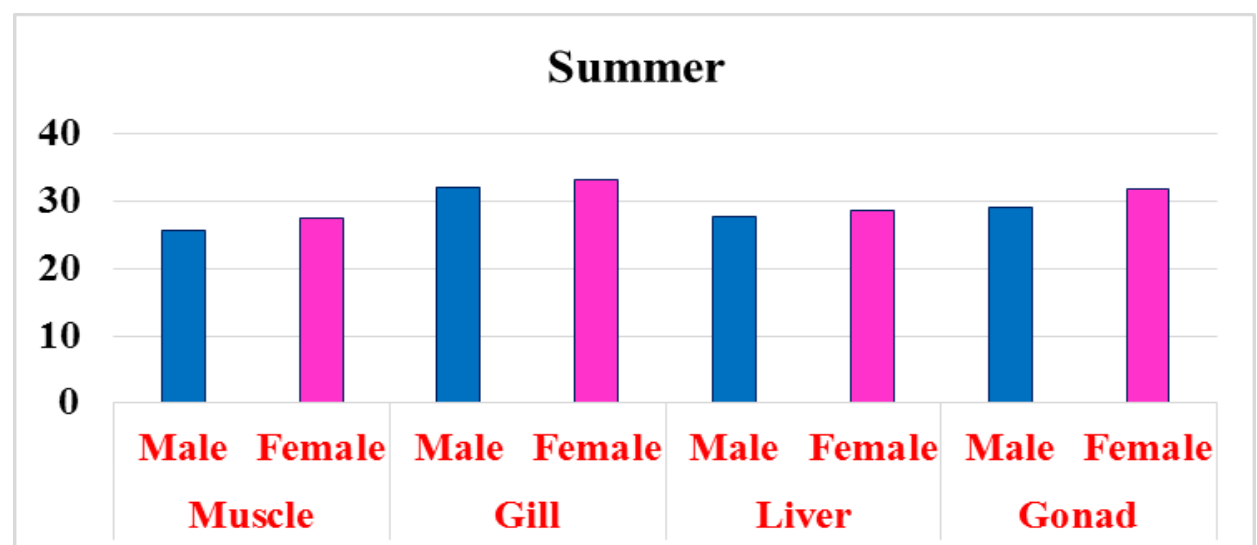

Figure 2 Seasonal variations in the Carbohydrate content (\%) of S. aculeata during summer Season.

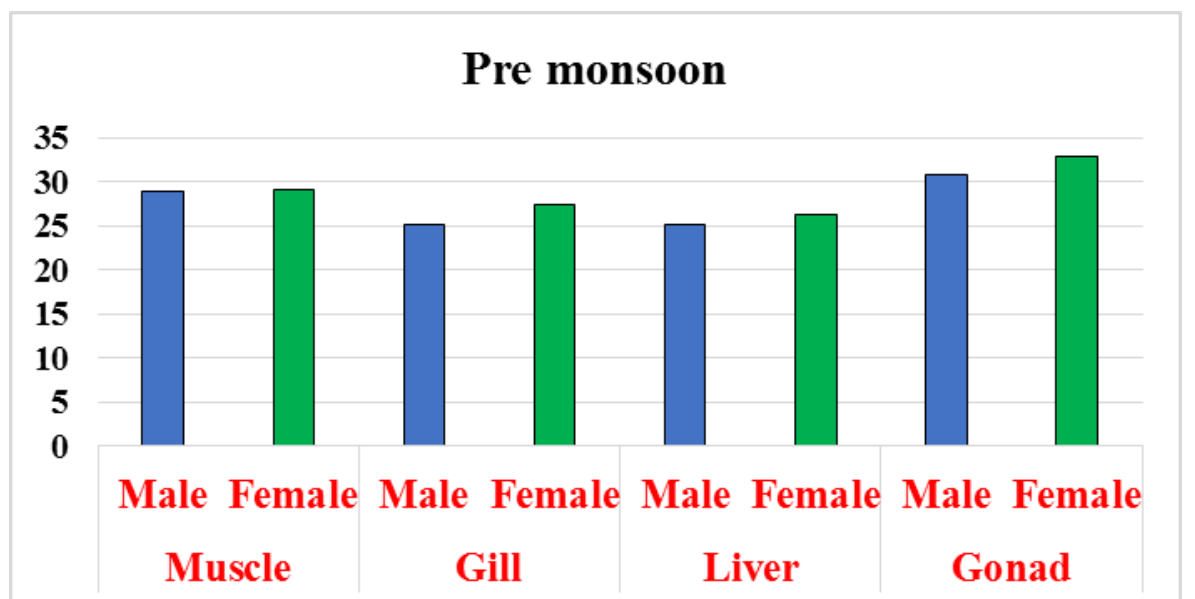

Figure 3 Seasonal variations in the Carbohydrate content (\%) of S.aculeata during pre monsoon Season. 


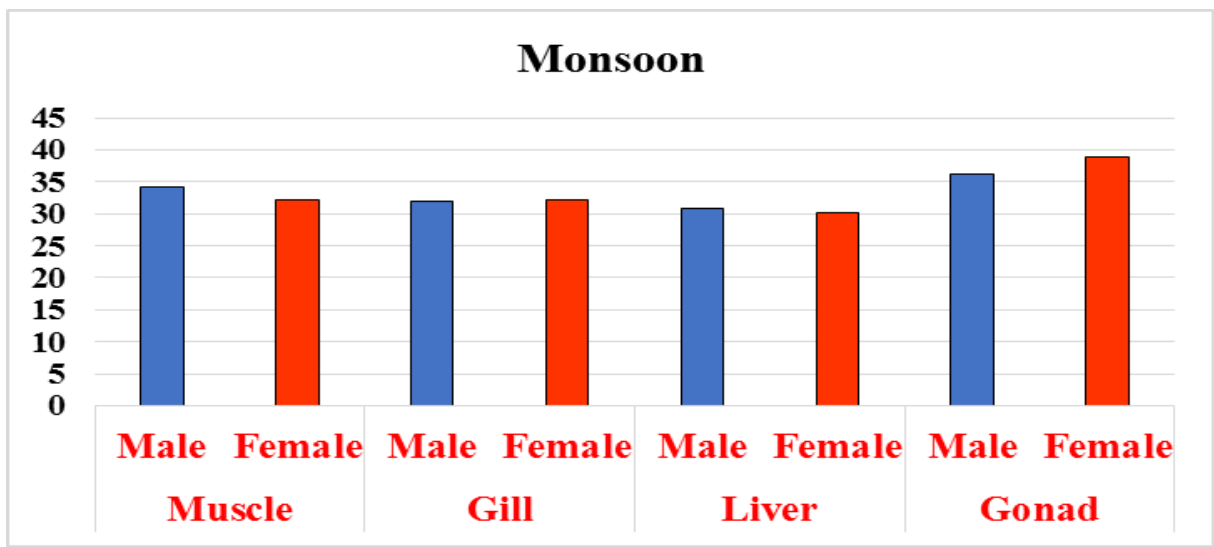

Figure 4 Seasonal variations in the Carbohydrate content (\%) of S.aculeata during monsoon Season.

\section{References}

[1] Oommen, Two Octopods new to Arabian Sea. Indian J. Fish. Volume 24, pp 1-2, 1977.

[2] Pasiyappazham Ramasamy, Namasivayam Subhapradha, Sadhasivam Sudharsan, Palaniappan Seedevi, Vairamani Shanmugam, and Annaian Shanmugam, African Journal of Food Science Volume. 6, Issue 22, pp 535-538, 2012.

[3] J. J. Watermann, Composition \& Quality of Fish Torry Research Station Edinburgh. 2000.

[4] R. L. Rosa, Nunes, and C. Sousa Reis, Seasonal changes in the biochemical composition of Octopus vulgaris Cuvier.1797 from three areas of the Portuguese coast. Bulletin of Marine science, Volume 7, Issue 2, pp 739-751, 2002.

[5] Raouf Kilada, and Rafik Riad, Seasonal reproduction biology of Uroteuthis duvauceli (Cephalopoda: Loliginidae) in northern red sea, Egypt. Journal of shellfish Research, National shellfish Association. Volume 29, Issue 4, pp 781-791, 2010.

[6] K. E. Harison, The role of nutrition in maturation reproduction and embryonic development of decapod crustaceans: a review, J. Shellfish. Res. Volume 9, pp 1-28, 1990.

[7] Raouf Kilada, Seasonal variations in biochemical composition of Loligo forbesi (Cephalopoda: Loliginidae) in the Mediterranean sea and the Gulf of suez, Egypt. J. Shellfish Res., Volume 27, pp 881-887, 2009.

[8] H. A. Rodriguez-Gonzalez, H. Henandez-Llamas, P. E. Villarreal, M. Saucedo,Gaciaulloat, and C. Rodriquez-Jaramillo, Gonadial development and biochemical composition of female crayfish Cherax quadricaninatus in relation to the gonadosomatic index at first maturation aquaculture. Volume 254, pp 637-645, 2006.

[9] R. Kilada, and R. Riad, Seasonal variations in biochemical composition of Loligo forbesi (Cephalopoda: Loliginidae) in the Mediterranean sea and the Gulf of suez, Egypt. J. Shellfish. 2009. 